\title{
Selenium Characterization in the Global Rice Supply Chain
}

PAUL N. WILLIAMS, ${ }^{\dagger}, \underset{\text { ENZO LOMBI, }}{\dagger}{ }^{\dagger}, \circ$ GUO-XIN SUN, ${ }^{\dagger}$ KIRK SCHECKEL," YONG-GUAN ZHU, ${ }^{*, \dagger,}$ - XINBIN FENG, ${ }^{*}$ JIANMING ZHU, " ANNE-MARIE CAREY, ${ }^{\ddagger}$ EUREKA ADOMAKO, ${ }^{\ddagger}, \nabla$

YOUSEFF LAWGALI, ${ }^{\ddagger}$ CLAIRE DEACON, AND ANDREW A. MEHARG*,

Research Center for Eco-Environmental Sciences, Chinese Academy of Sciences, Beijing, 100085, China., Institute of Biological and Environmental Sciences, University of Aberdeen, Cruickshank Building, St. Machar Drive, Aberdeen, AB24 3UU, U.K., Department of Agriculture and Ecology,

Faculty of Life Science, University of Copenhagen, Thorvaldsensvej 40, 1871 Frederiksberg C, Denmark, National Risk Management Research Laboratory, U.S. Environmental Protection Agency, 5995 Centre Hill Avenue, Cincinnati, Ohio 45224, Institute of Urban Environment, Chinese Academy of Sciences, Xiamen 361003, China, Institute of Geochemistry, Chinese Academy of Sciences, Guiyang 100049, China, and Department of Botany, University of Ghana, Legon, Accra, LG 55, Ghana

Received March 3, 2009. Revised manuscript received May 14, 2009. Accepted May 14, 2009.

For up to 1 billion people worldwide, insufficient dietary intake of selenium $(\mathrm{Se})$ is a serious health constraint. Cereals are the dominant Se source for those on low protein diets, as typified by the global malnourished population. With crop Se content constrained largely by underlying geology, regional soil Se variations are often mirrored by their locally grown staples. Despite this, the Se concentrations of much of the world's rice, the mainstay of so many, is poorly characterized, for both total Se content and Se speciation. In this study, 1092 samples of market sourced polished rice were obtained. The sampled rice encompassed dominant rice producing and exporting countries. Rice from the U.S. and India were found to be the most enriched, while mean average levels were lowest in Egyptian rice: $\sim 32$-fold less than their North American equivalents. By weighting country averages by contribution to either global production or export, modeled baseline values for both were produced. Based on a daily rice

* Corresponding author tel: +86 1062936940 ; fax: +86 1062936940 ; e-mail (Y.-G.Z.) ygzhu@rcees.ac.cn. tel: +44 (0) 1224 272264; fax: +44 (0)1224 272703; e-mail (A.A.M) a.meharg@abdn.ac.uk.

${ }^{\dagger}$ Research Center for Eco-Environmental Sciences, Chinese Academy of Sciences.

${ }^{\ddagger}$ Institute of Biological and Environmental Sciences, University of Aberdeen.

${ }^{\dagger}$ Faculty of Life Science, University of Copenhagen.

" National Risk Management Research Laboratory, U.S. Environmental Protection Agency.

${ }^{\perp}$ Institute of Urban Environment, Chinese Academy of Sciences.

\# Institute of Geochemistry, Chinese Academy of Sciences.

${ }^{\nabla}$ Department of Botany, University of Ghana.

Present address: Centre for Environmental Risk Assessment and Remediation, University of South Australia, Building X, Mawson Lakes Campus Mawson Lakes, South Australia, SA-5095 Australia, and CRC CARE, P.O. Box 486, Salisbury, South Australia 5106, Australia. consumption of $300 \mathrm{~g} \mathrm{day}^{-1}$, around $75 \%$ of the grains from the production and export pools would fail to provide $70 \%$ of daily recommended Se intakes. Furthermore, Se localization and speciation characterization using X-ray fluorescence ( $\mu$-XRF) and X-ray absorption near edge structure ( $\mu$-XANES) techniques were investigated in a Se-rich sample. The results revealed that the large majority of Se in the endosperm was present in organic forms.

\section{Introduction}

Being a crucial component of both glutathione peroxidase and thioredoxin reductase, selenium (Se) plays fundamental roles in both antioxidant and thyroid hormone production, in addition to a plethora of other structural and metabolic functions (1-3). Depletion physiologies have been associated with muscular weakness, myalgia, cartilage dysfunction, reproductive impairment heart failure, and associated with senility and furthering cognitive decline in the elderly (1-3). Conversely, although albeit less prevalent, chronic Se toxicosis or selenosis resulting from excess dietary Se intake has been implicated as a cause of hair and nail loss, skin lesions, liver enlargement in addition to gastrointestinal and neurological pathologies (4). The narrow range of dietary intake from which nutritional benefits are conferred $\left(55-200 \mu \mathrm{g} \mathrm{g}^{-1}\right)(1)$, the enormous variability in Se concentrations encountered not just between food types but also from the same foods grown in different regions (5) and under differing agricultural management regimes (6), hampers identification, monitoring and mitigation of populations and demographic groups with nonoptimal Se intakes. Although, problematic to quantify, upper estimates for Se-deficiency alone indicate up to $15 \%$ of the world's population could be affected (3).

Approximately, $50 \%$ of the human population are reliant upon paddy rice for sustenance (7). Not only can rice contribute up to approximately $80 \%$ of energy intake in some regions (8), but it can account for a significant proportion of their daily dose of protein and micronutrients (9). Therefore, optimising levels of Se in rice can have dramatic impacts on human Se status, for example villagers in Se enriched regions of northern India can obtain $\sim 90 \%$ of their Se intake solely from cereals (10); however, only around $20 \%$ is reached in settlements found in areas with lower Se soil baselines (10).

Many of the factors limiting rice Se levels are geochemical in origin and subject to natural variation in mineral and soil composition. Decreased Se availability, however, in flooded soils can exacerbate the problem, resulting in less plant uptake than in aerobic agro-systems. This is because under reduced conditions $\mathrm{Se} /$ metal insoluble complexes precipitate, because of the thermodynamic stability of selenite $\left(\mathrm{SeO}_{3}{ }^{2-}\right)$ and selenide $\left(\mathrm{Se}^{2-}\right)(11)$. Bioavailability and subsequent Se uptake is additionally curtailed as paddy clay minerals prove highly efficient in adsorbing Se (12).

A number of mitigation options exist to protect against Se deficiency disease. As outlined in reviews by Broadley et al. (13), White and Broadley (14). and Welch and Graham (15), biofortification approaches that enhance the bioavailable concentrations of essential elements in edible components of cereals and other crop plants are promising. In planta Se content increases can be achieved by both agronomic or genetic biofortification, with either the addition of fertilizers, or breeding/selection for plants with higher uptakes (13-15). However, this requires the identification of regions that would benefit most from biofortification programs. In addition to biofortification, Se intakes can also be increased with nutrient 
TABLE 1. Descriptive Statistics of Total Se Concentrations in Market Bought White Rice Produced in Different Countries

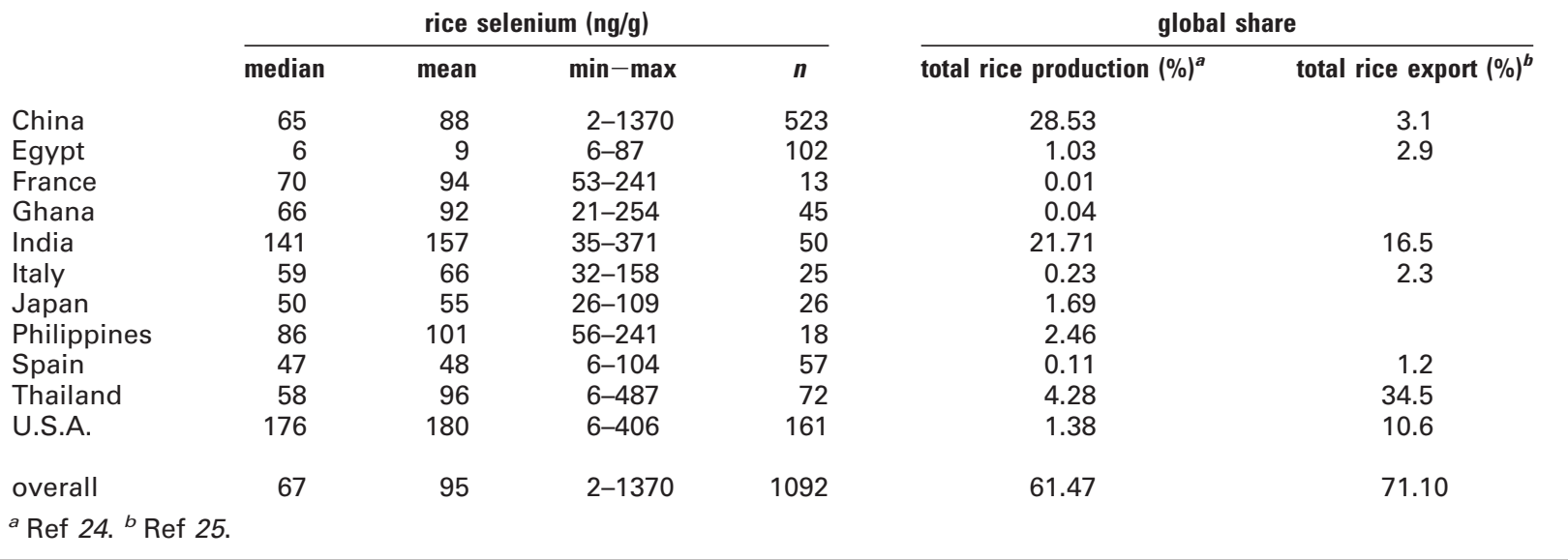

enriched food supplements (16). Used in combination with biofortification approaches, not only can Se uptakes be optimized but dietary exposure to specific Se-species can be tailored more effectively.

Optimization of Se intakes in Se-deficient populations is not really the definitive health point per se, as there is increasing evidence pertaining to the speciation relevance of Se in foods (17). In particular monomethylselenol and its precursors methyl-selenocysteine (Se-MeSeCys) and $\alpha$-glutamylderivatives have been suggested to be the key anticarcinogenic Se species (18-20). To date, speciation of Se in rice has not been investigated with in situ techniques such as X-ray absorption near edge structure (XANES). However, this technique has been employed to assess Se speciation in various plants including Se-hyperaccumulators (21). Early evidence based on column chromatography revealed the presence of Se methione (Se-Met) but were limited by the methodology used (22).

Unlike geological Se mapping, global rice grain Se concentrations are poorly characterized. To address this, we conducted a worldwide market-basket survey of Se concentrations in white polished rice to determine variation in national rice grain Se concentrations. From this, we were able to model Se concentration distributions for both the global rice production and rice export pools, respectively. To compliment global Se baseline estimates, detailed evidence is presented in the form of in situ speciation characterization and spatial distribution of naturally occurring Se in an enriched rice grain sample.

\section{Experimental Methods}

Global Rice Survey. A total of 1092 samples of white (polished) rice were obtained from market stores between 2005 to 2008 . Table 1 provides a breakdown of the sources or country of origin from which the rice was produced but not necessarily bought. With the exception of 134 U.S. bought samples that were featured in the survey by Williams et al. (23) all the presented data are new. Although, neither practical nor feasible to source from every rice producing country, a robust survey was achieved that encompassed countries that equate to $61.5 \%$ of the worlds total rice production (24) (Table 1). Considered on the basis of the global export pool, then the countries sampled represented $71.1 \%$ (25) and reflect the fact that rice was obtained from vendors as opposed from being directly from the field. With the convergence of numerous rice production and distribution networks and the mixing process of grain therein, market basket surveys for cereals continue to be employed to assess dietary exposures from regional (26), national (27) and global populations (28). They also play a fundamental role in risk assessment and underpin much of the current maximum concentration level legislation (29). Since approximately $91 \%$ of the world's global rice production is located in Asia, this became the predominant focus for survey campaigns, with samples being collected from the countries that are producers, consumers, and exporters of rice (Table 1).

Total Concentrations. All rice samples were powdered, oven-dried at $70{ }^{\circ} \mathrm{C}$, until a constant weight was reached, and then weighed into pre-acid-washed, preweighed polypropylene $50 \mathrm{~mL}$ digestion tubes. Standard digestion and analysis methodologies using ICP-MS were adapted from Williams et al. (30). Sample digestion batches were accompanied by analytical blanks, rice flour certified reference material (CRM) (NIST 1568a or GBW 10010) and blank spikes. For samples found to be below the limit of detection (LOD) an arbitrary value of $50 \%$ LOD was used. All data presented in this study are expressed on a dry weight basis.

Quality Control. The median LOD from 14 sample runs was $0.07 \mu \mathrm{g} \mathrm{L}^{-1}$, being in agreement with Williams et al. (30). Based on sample weights of $0.200 \mathrm{~g}$ and digests being diluted to a mass of $50.000 \mathrm{~g}$, this would equate to a Se level in the rice grain of $17 \mathrm{ng} \mathrm{g}^{-1}$. Mean CRM and spike recoveries were $111 \%$ and $80 \%$, respectively.

Localization and Speciation of Se in Enriched Rice. Local market rice was obtained from Jianshi county, Enshi (Hubei Province) in South-Central China, in a Se-elevated region. Selenium concentration in bran, brown rice and polished rice are $17.2,9.2$, and $8.9 \mu \mathrm{g} \mathrm{g}^{-1}$. These concentrations are much larger than the average concentration in the samples from the global survey, but follow the same trend of Se concentration in bran, brown rice and polished rice. The rationale behind this choice resides in the challenges to collect distribution maps and especially XANES spectra on very dilute samples.

Preparation of Bulk Husk, Bran, and Endosperm Grain Fractions for XANES. Raw rice samples were manually dehulled, while the caryopsis was further separated mechanically into bran and endosperm fractions in accordance with methodologies reported in Sun et al. (31). All grain components were then separately powdered in a benchtop mill. BulkXANES spectra were collected at Sector 20-ID (PNC/ XOR) at the Advanced Photon Source (APS), Argonne National Laboratory (32). The electron storage ring operated at $7 \mathrm{GeV}$ with a top-up fill status. Sector 20-ID includes a liquid nitrogen cooled Si (111) double crystal monochromator, which was calibrated using a Se foil $(12658 \mathrm{eV})$. The samples were mounted in a cryostat sample holder to hinder beam induced artifacts. XANES spectra were collected in fluorescence mode with a solid-state 13-element $\mathrm{Ge}(\mathrm{Li})$ detector. Se standards were analyzed as powders (diluted in $\mathrm{BN}$ ) and 


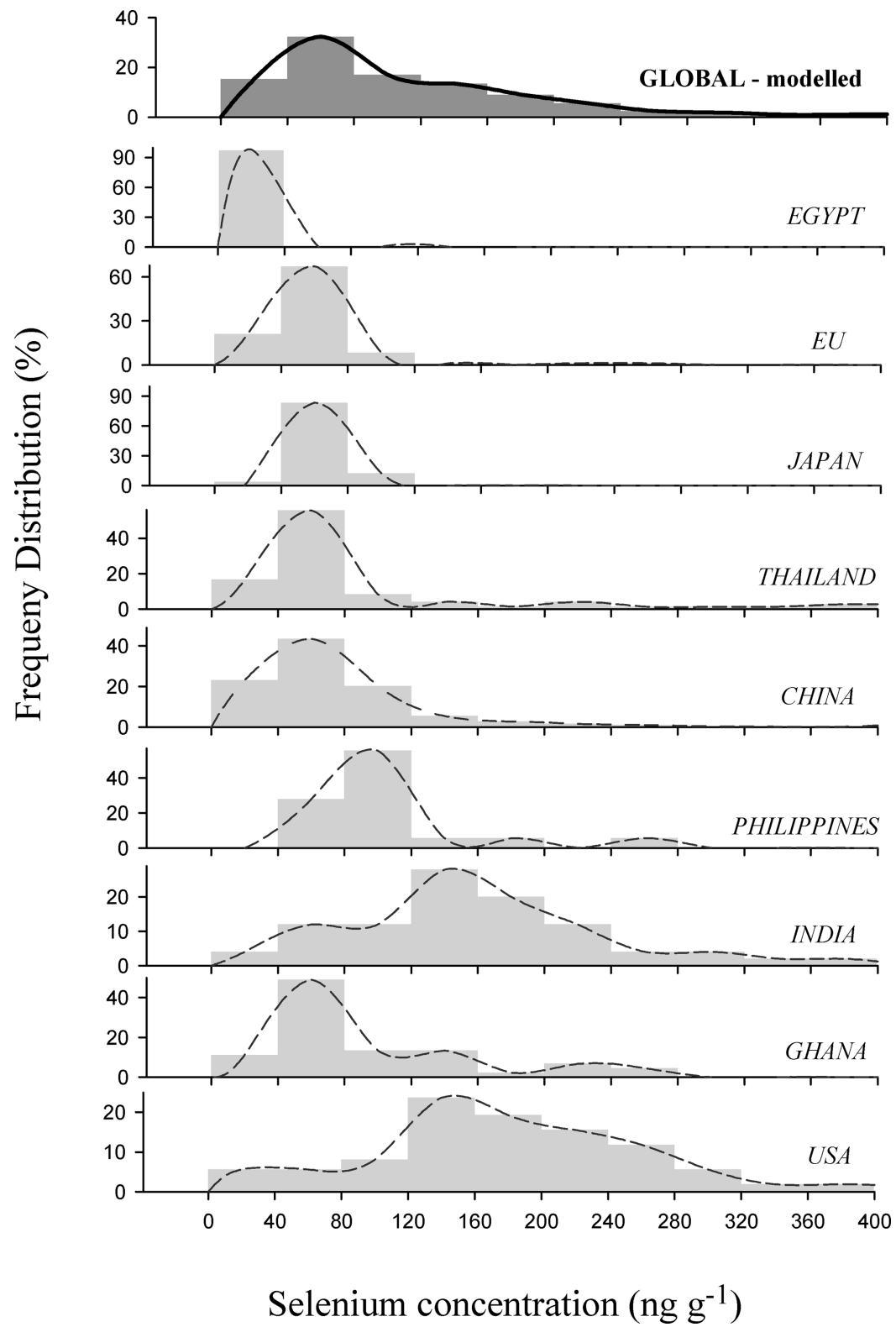

FIGURE 1. Se distribution in rice from different countries. An explanation of modeled global distribution is provided within the text.

included Na selenite, Na selenate, SeCystine (SeCys), and Se Methionine (SeMet). In addition a spectrum of Se-MeSeCys was kindly provided by Prof. Elizabeth Pilon-Smits (Biology Department, Colorado State University). The XANES data (average of 3 scans) of the samples were normalized and analyzed by linear combination fitting (LCF) using Athena (33). It should be emphasized here that the LCF approach is not free of uncertainties and limitations. The correctness of the LCF is affected by the, often a priori, choice of the standards that will be used in the fitting procedure (34). Therefore, the results obtained will depend by the choices of the standards that will be used.

Sample Protocol for $\mu$-XRF and $\mu$-XANES. Flattened longitudinal and transverse sections were obtained by fracturing grains. These were then mounted onto a metal plinth with adhesives to enable microtome thin sectioning. Procedures described in Lombi et al. (35) were employed to ensure that the integrity of nonembedded samples was maintained during cutting. Two $70 \mu \mathrm{m}$ thick sections, one from each of the spatial planes, were selected for in situ analysis. Spot sizes of $5 \mu \mathrm{m}$ were employed in both $\mu$-XRF and $\mu$-XANES determination, with elemental mapping using step sizes of $10 \mu \mathrm{m}$. The $\mu$-XANES were analyzed as described above.

\section{Results}

Global Rice Survey. Between Country Variation in Selenium Concentrations. There was a highly significant difference in average Se concentrations between countries of origin (Kruskal-Wallis, $p<0.001$ ). Egyptian rice was the lowest with mean and median values of 9 and $6 \mathrm{ng} \mathrm{g}^{-1}$, respectively. Out of 102 samples, $93 \%$ were below $20 \mathrm{ng} \mathrm{g}^{-1}$, while $83 \%$ failed to exceed $10 \mathrm{ng} \mathrm{g}^{-1}$. Data in the literature regarding the Se concentrations in North African rice are scant. Although Hussein et al. (36), as part of a wider investigation into dietary Se intake from the Egyptian population, report levels to be comparable to this study at $3 \mathrm{ng} \mathrm{g}^{-1}$. These averages for Egyptian rice are similar to the minimum boundary levels reported in Se deficient regions of Sri Lanka of between 5-7 $n g \mathrm{~g}^{-1}$ (37).

Mean and median averages for the U.S. were the highest, 32- and 21-fold higher than for Egyptian at 176 and $180 \mathrm{ng}$ $\mathrm{g}^{-1}$, respectively. There is considerable regional diversity in 

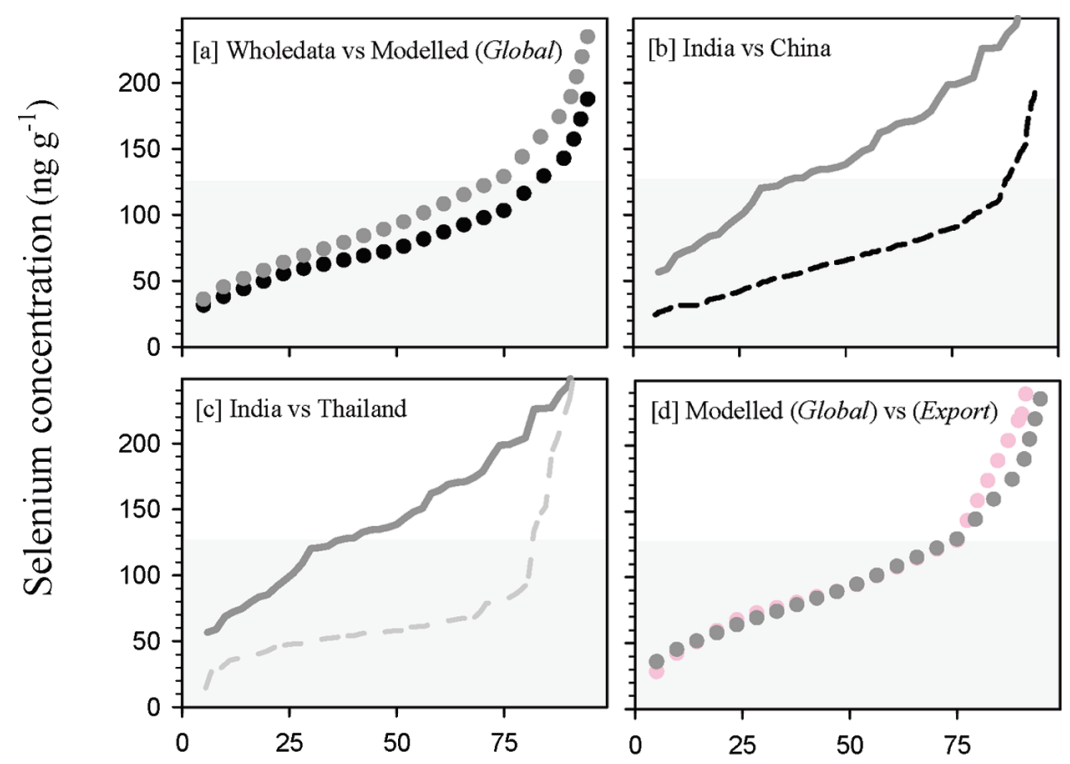

Cummulative Frequency Distribution (\%)

FIGURE 2. Distribution summary of Se concentrations in white rice. Comparison of [a] wholedata (blank dots) and modeled global baseline (dark gray). [b] The top two rice producing countries, India (dark gray line) and China (dashed black line). [c] The top two rice exporting countries Thailand (dashed black line) and India (dark gray line). [d] Modeled global and export baselines. Gray shading represents grain Se concentrations that would fail to provide $\mathbf{7 0} \%$ of the daily recommended Se intake based on a rice consumption of $300 \mathrm{~g} \mathrm{day}^{-1}$.

geochemical Se levels in the U.S., and this is mirrored by the broad spectrum of Se concentrations found in U.S. rice, as depicted in Figure 1. Kelly et al. (38) found median concentrations of Se in rice from the state of Arkansas to average $256 \mathrm{ng} \mathrm{g}^{-1}(n=6)$, while in California the median for samples comprising of both white and brown (unpolished) rice was $57 \mathrm{ng} \mathrm{g}^{-1}(n=27)$. It is important to note that about $80 \%$ of all U.S. rice is produced in the South Central area, U.S. rice was sourced from regional areas from U.S. supermarkets at a frequency proportional to their production (23).

The range observed in this study for Indian rice is supported by Kelly et al. (38) who found levels from 5-233

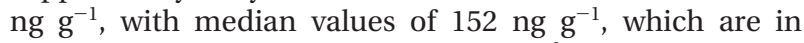
agreement with our findings of $141 \mathrm{ng} \mathrm{g}^{-1}$ (Table 1), and the mean from 8 districts, encompassing 91 samples, from northern India was $159 \pm 57 \mathrm{ng} \mathrm{g}^{-1}$ (39). Although unable to determine the geographic distribution of the samples within India, they would duly reflect the export pool and be well mixed, as they were obtained from multiple markets encompassing 3 countries and 2 continents (28).

U.S. and India exhibited normal distributions while the Asian Pacific, African, and EU countries were positively skewed, echoing a higher proportion of lower Se rice levels and an infrequency of elevated grains (Figure 1). Intracountry Se concentration ranges varied extensively, with the lowest differences between minimal and maximum levels in rice being 82 and $84 \mathrm{ng} \mathrm{g}^{-1}$ from Egypt and Japan, respectively. Ranges from India, U.S.A., and Thailand were between $4-6$ fold higher. China possessed the greatest variation of 1368 ng g ${ }^{-1}$, although only $5 \%$ and $2.5 \%$ of the samples $(n=523$; Table 1) exceeded 200 and $270 \mathrm{ng} \mathrm{g}^{-1}$, respectively.

Global Modeling, Export/Production. Mean and median Se concentrations for the whole data set are compared with that of individual countries (Table 1). A more realistic interpretation, however, of the distribution summaries is achieved by scaling with respect to individual countries contribution to global rice production, as conducted by Meharg et al. (28) for rice grain arsenic concentrations. By modeling each country's percentage contribution to all the countries rice production, with the weighted individual distributions from each country summed, an overall esti-

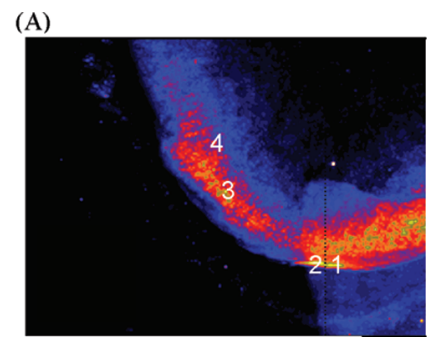

(B)

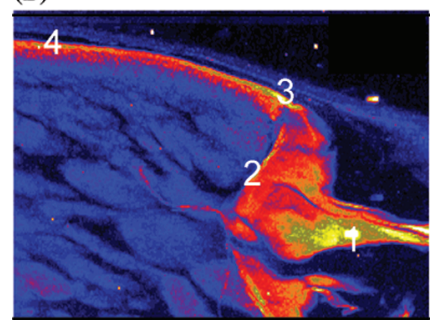

FIGURE 3. $\mu$-XRF elemental map of Se localization in Chinese rice. Labels $1-4$ denote regions characterized for Se speciation by $\boldsymbol{\mu}$-XANES.

mated global distribution is generated. Furthermore, not only can the Se global baseline be determined but also export baseline values (Figure 2 a,d), by substituting contribution to rice production with that of export (Table 1). Figure $2 a-d$, shows the modeled baselines for both export and total pools, with those for both the largest total production and exporting countries.

Comparison of the modeled baseline with that of Egyptian rice reveals that $99 \%$ of the grain fell below the 10 th percentile of the global distribution (See Supporting Information, Figure S1). Median values though for U.S. and Indian rice exceeded the modeled 75th percentiles. The Se concentration in modeled export pools was not appreciably different from that of the estimated global baseline, although an increase in Se concentrations above the $75 \%$ cumulative frequency represents a greater role of U.S. rice in export compared to total global production (Figure 2a). 
TABLE 2. Summary of Rice Se Speciation Trends Determined by $\mu$-XANES ${ }^{a}$

\begin{tabular}{|c|c|c|c|c|c|c|c|}
\hline sample & selenate & selenite & SeMet & SeCys & MeSeCys & inorganic Se & goodness of fit $\left(\chi^{2}\right)$ \\
\hline \multicolumn{8}{|c|}{ bulk } \\
\hline husk & 14.7 (1.3) & $30.2(1.7)$ & $32.7(8.1)$ & $8.3(5.7)$ & $14.1(5.8)$ & $45 \%$ & 0.16 \\
\hline bran & $25.0(2.3)$ & $28.2(2.5)$ & & & $46.8(12.2)$ & $53 \%$ & 0.12 \\
\hline endosperm & & $5.5(1.3)$ & $39.2(1.2)$ & & $55.3(1.4)$ & $5 \%$ & 0.07 \\
\hline \multicolumn{8}{|c|}{ microanalyses } \\
\hline cross spot 1 & & $7.8(0.9)$ & & & $92.2(1.5)$ & $8 \%$ & 1.11 \\
\hline cross spot 2 & & $8.1(0.9)$ & & & $91.9(1.3)$ & $8 \%$ & 0.23 \\
\hline cross spot 3 & & $7.5(1.4)$ & & & $92.5(2.1)$ & $8 \%$ & 0.27 \\
\hline cross spot 4 & & & & & 100 & $0 \%$ & 0.24 \\
\hline long. spot 1 & & $13.3(1.2)$ & & $6.7(0.8)$ & 80.7 (1.4) & $13 \%$ & 0.31 \\
\hline long. spot 2 & & $3.7(0.6)$ & & & $96.3(1.5)$ & $4 \%$ & 0.33 \\
\hline long. spot 3 & & $7.2(1.1)$ & & & $92.8(1.3)$ & $7 \%$ & 0.33 \\
\hline long. spot 4 & & $14.4(1.7)$ & & & $85.6(2.3)$ & $14 \%$ & 0.41 \\
\hline
\end{tabular}

Localization and Speciation of Se in Enriched Rice. Se Localization in the Grain. $\mu$-XRF maps clearly show Se differentiation patterns corresponding to specific tissues within the whole grain and caryopsis, with increases in concentration denoted by color changes in a relative scale that ranges from black/blue (low) to yellow/white (high). Considering the cross section scan (Figure. 3a) first, which encompasses one lateral and the morphological ventral grain surface; there is elevated Se accumulation in outer regions of the grain, specifically corresponding to pericarp and aleurone tissues that comprise the bran layer. Highest Se intensities are observed in grain tissues, such as the chalazal zone, that share a close proximity to the ovular vascular trace (OVT). Although upon grain maturity the OVT is defunct, during development it is the transport component supplying all the nutrient requirements to the aleurone and endosperm (40). The data reveals that endosperm is also subject to Se infiltration and that the focal point is also associated with the OVT. This distribution pattern is very similar to what is observed in the case of S in rice grains (35). S and Se share similar metabolic pathways in plants (14).

Structural features in the longitudinal scan images are resolved (Figure $3 \mathrm{~b}$ ). The section presented is sliced from the dorsal grain surface, where the germ layer is prominent (40). Although, bran and germ recorded the greatest Se concentrations, the distribution of Se in the endosperm is striking. Unlike the cross section, where the chalazal zone facilitated diffusion from outer layers inward the demarcation between tissue types and Se intensity is more defined.

Speciation of Se Using $\mu$-XANES. The spectra obtained from the bulk and micro analysis are provided in the Supporting Information (Figure S2-S4). There was considerable Se-speciation variation between grain structures, as documented in Table 2, with the goodness of fit $\left(\chi^{2}\right)$ of the LCF for the bulk samples, not exceeding 0.16 . Variation in the microanalysis was marginally higher, with region 1 on the latitudinal section (Figure $3 a$ ) recording a $\chi^{2}>1$, although a second reading was taken adjacently that compared very favorably with fits of less than 0.25 (Table 2).

In bulk husk and bran, the relative proportions of inorganic Se $\left(\mathrm{Se}_{i}\right)$ were $\sim 10$ times higher than those of endosperm. Se-Met, Se-Cys, and Se-MeSeCys species were all detected in husk, with Se-Met being dominant. Intriguingly, in comparison with husk, Se-MeSeCys was the only organic Se $\left(\mathrm{Se}_{\mathrm{org}}\right)$ species detected in bran fractions and contributed to $47 \%$ of total Se. With $\mathrm{Se}_{i}$ largely absent from endosperm tissue, $94.5 \%$ of the detected species were $\mathrm{Se}_{\mathrm{org}}$, and of that $59 \%$ were identified as Se-MeSeCys. The spectra of Se-MeSeCys is similar to those of the other two organic species. However, removing this spectra during the LCF procedure resulted in a poorer fit of the husk and endosperm Se XANES spectra.

This contrasts with speciation patterns determined in rice from the Se-enriched region of Enshi in South-Central China where Se-Met contributed to 68 and $81 \%$ of the extractable Se species detected (22). However, this is not surprising since in the Beilstein et al. (22) study Se speciation was performed using column chromatography after an HCL extraction and Se-MeSeCys was not included in the standard compounds investigated. Speciation trends in bulk grain samples were corroborated by $\mu$-XANES spot analysis and regions specifically elevated in Se were targeted. As Se-MeSeCys concentrations were high in micro-XANES scans, this indicates that while the other $\mathrm{Se}_{\text {org }}$ species probably diffused throughout the specimens, Se-MeSeCys is the phase that tends to accumulate in the Se enriched areas of the bran.

It should be kept in mind that these results were obtained from one selected rice grain sample and further investigation is needed to assess whether the organic species identified in this study are present across various rice cultivars and Se concentrations. Furthermore, direct identification and quantification of the Se species should be confirmed with another analytical technique because of the limitations of the XANESLCF procedure mentioned above.

\section{Discussion}

Implications of Rice Consumption for Se Intake. Traditional rice diets do not provide Se levels adequate to maintain health, unless other sources of Se rich food are additionally consumed. Far from being restricted to one region or location, results from this and other surveys reveal the problem to be widespread, for example, based on a recommended minimum daily (RDI) Se intake of $55 \mu \mathrm{g}$ day $^{-1}$ and a rice consumption of $300 \mathrm{~g} \mathrm{day}^{-1}$, around $75 \%$ of the world's rice and export rice pool, based on the modeled baseline, would be insufficient at providing more than $70 \%$ of the Se RDI. There is choice; however, depending on where rice is sourced. With both China, being the foremost rice producer, and Thailand as the second largest contributor to rice export (Table 1), tightly following the modeled baseline. Whereas, it is shown that for the largest exporter and second highest rice producer, India, levels are much higher with only $35 \%$ being insufficient.

One way of offsetting suboptimal daily Se intakes is to use Se-enriched rice. Becoming already an established practice within China (41), this strategy principally takes two forms. The first is well documented and involves biofortification through fertilization and foliage spray applications to manipulate rice with very low Se levels, bringing them up to baseline. The second is to use highly enriched rice as a 
food supplement in its own right. With its easy integration into the existing food habits of rice consuming populations this could be a simple way to bolster the health of key at risk groups, that is, pregnant women, young children and the infirm. For a scenario based on a dietary rice intake of $300 \mathrm{~g}$ day $^{-1}$, with concentrations of $50 \mathrm{ng} \mathrm{Se} \mathrm{g}^{-1}$, substituting as little as $25 \mathrm{~g}$ highly Se enriched rice, with a concentration of $1,000 \mathrm{ng} \mathrm{g}^{-1}$, would equate to a $\sim 2.5$-fold increase in Se intake, making rice alone account for $70 \%$ of the RDI.

With each type of Se supplement source, however, there are associated limitations. Utilization of Se endosperm (polished white rice), maybe the preferable rice fraction of use, despite enrichment in the bran, as the collocation of metal(loid)s, such as arsenic and lead along with Se in bran layers may preclude their use for human consumption (31). Furthermore, the $\mu$-XRF investigation revealed that Se distribution is not only limited to the aleurone/pericarp layer of rice as observed for other micronutrients such as Fe (42) but extends into the endosperm. However, Cd concentration should additionally be monitored as white rice can be problematic with respect to this element $(26,42)$.

With rice being poorly characterized for Se speciation, our findings show that organic Se compounds represent the majority of the total $\mathrm{Se}$ in the endosperm and further investigation is needed to assess whether this is a common occurrence across rice samples. Furthermore, more focus should be directed toward protecting those whose health is being compromised as a result of the global Se-deplete rice pool.

\section{Acknowledgments}

Natural Science Foundation of China (20720102042), Chinese Academy of Sciences (KZCX1-YW-06-03), CAS Research Fellowship for International Young Researchers and the Royal Society of Edinburgh's International Exchange programme. Elizabeth Pilon-Smits (Biology Department, Colorado State University), for generously providing a XANES spectrum of methylselenocysteine. PNC/XOR facilities at the Advanced Photon Source and research at these facilities are supported by the U.S. Department of Energy, Basic Energy Sciences, a major facilities access grant from NSERC, the University of Washington, Simon Fraser University and the Advanced Photon Source. Use of the Advanced Photon Source is also supported by the U.S. Department of Energy, Office of Science, Office of Basic Energy Sciences, under Contract DEAC02-06CH11357. The U.S EPA through its Office of Research and Development funded and managed a portion of the research. It has not been subject to Agency review and, therefore, does not necessarily reflect the views of the Agency. No official product endorsement should be inferred.

\section{Supporting Information Available}

Purchasing details for market rice, boxplots of grain Se levels by country of origin and XANES spectra. This material is available free of charge via the Internet at http:/ / pubs.acs.org.

\section{Literature Cited}

(1) Rayman, M. P. The importance of selenium to human health. Lancet 2000, 356, 233-241.

(2) Beckett, G. J.; Arthur, J. R. Selenium and endocrine systems. J. Endocrinol. 2005, 184, 455-465.

(3) Combs, G. F. Selenium in global food systems. Br. J. Nutr. 2001, 85, 517-547.

(4) McLaughlin, M. J.; Parker, D. R.; Clarke, J. M. Metals and micronutrients-Food safety issues. Field Crop Res. 1999, 60, 143-163.

(5) Rayman, M. P. Food-chain selenium and human health: Emphasis on intake. Br. J. Nutr. 2008, 100, 254-268.

(6) Zhao, F.-J.; Lopez-Bellido, F. J.; Gray, C. W.; Whalley, R.; Clark, L. J.; McGrath, S. P. Effects of soil compaction and irrigation on the concentrations of selenium and arsenic in wheat grains. Sci. Total Environ. 2007, 372, 433-439.
(7) Harvest Plus. Biofortified Rice. http://www.harvestplus.org (Accessed Dec. 2008).

(8) Tetens, I.; Hels, O.; Khan, N. L.; Thilsted, S. H.; Hassan, N. Ricebased diets in rural Bangladesh: How do different age and sex groups adapt to seasonal changes in energy intake. Am. J. Clin. Nutr. 2003, 78, 406-413.

(9) Hels, O.; Hassan, N.; Tetens, I.; Thilsted, S. H. Food consumption, energy, and nutrient intake and nutritional status in rural Bangladesh: Changes from 1981-82 to 1995-96. Eur. J. Clin. Nutr. 2003, 57, 586-594.

(10) Hira, C. K.; Partal, K.; Dhillon, K. S. Dietary selenium intake by men and women in high and low selenium areas of Punjab. Public Health Nutr. 2003, 7, 39-43.

(11) Kirk, G. The Biogeochemistry of Submerged Soils; Wiley: Hoboken, NJ, 2004.

(12) Johnsson, L. Selenium uptake by plants as a function of soil type, organic matter content, and pH. Plant Soil 1991, 133, $57-64$.

(13) Broadley, M. R.; White, P. J.; Bryson, R. J.; Meacham, M. C.; Bowen, H. C.; Johnson, S. E.; Hawkesford, M. J.; McGrath, S. P.; Zhao, F.-J.; Breward, N.; Harriman, M.; Tucker, M. Biofortification of UK food crops with selenium. Proc. Nutr. Soc. 2006, 65, 169-181.

(14) White, P. J.; Broadley, M. R. Biofortification of crops with seven mineral elements often lacking in human diets-Iron, zinc, copper, calcium, magnesium, selenium and iodine. New Phytol. 2009, 182 (1), 49-84, 10.1111/j.1469-8137.2008.02738.x.

(15) Welch, R. M.; Graham, R. D. Agriculture: The real nexus for enhancing bioavailable micronutrients in food crops. J. Trace Elem. Med. Biol. 2005, 18, 299-307.

(16) Rayman, M. P. The use of high-selenium yeast to raise selenium status: How does it measure up. Br. J. Nutr. 2004, 92, 557-573.

(17) Rayman, M. P.; Goenaga Infante, H.; Sargent, M. Food-chain selenium and human health: Spotlight on speciation. Br.J. Nutr. 2008, 100, 238-253.

(18) Ellis, D. R.; Salt, D. E. Plants, selenium and human health. Curr. Opin. Plant Biol. 2003, 6, 273-279.

(19) Ip, C. Lessons from basic research in selenium and cancer prevention. J. Nutr. 1998, 128, 1845-1854.

(20) Finley, J. W. Increased intakes of selenium-enriched foods may benefit human health. J. Sci. Food Agric. 2007, 87, 1620-1629.

(21) Freeman, J. L.; Zhang, L. H.; Marcus, M. A.; Fakra, S.; McGrath S. P.; Pilon-Smits, E. A. H. Spatial Imaging, Speciation, and Quantification of Selenium in the Hyperaccumulator Plants Astragalus bisulcatus and Stanleya pinnata. Plant Physiol. 2006, 142, 124-134.

(22) Beilstein, M. A.; Whanger, P. D.; Yang, G. Q. Chemical forms of selenium in corn and rice grown in a high selenium area of China. Biomed. Environ. Sci. 1991, 4, 392-398.

(23) Williams, P. N.; Raab, A.; Feldmann, J.; Meharg, A. A. Market basket survey shows elevated levels of as in South Central U.S. processed rice compared to California: Consequences for human dietary exposure. Environ. Sci. Technol. 2007, 41, 2178-2183.

(24) FAOSTAT Database2008. FAO, Rome 22nd Sept 2008.

(25) International trade commodities. Leading rice export countries 2008. http://internationaltradecommodities.suite101.com/article. cfm/leading_rice_export_countries (accessed Jan 2009).

(26) Williams, P. N.; Lei, M.; Sun, G.-X.; Huang, Q.; Lu, Y; Deacon, C.; Meharg, A. A.; Zhu, Y.-G. Occurrence and partitioning of cadmium, arsenic and lead in mine impacted paddy rice: Hunan, China. Environ. Sci. Technol. 2009, 43, 637-642.

(27) Schoof, R. A.; Yost, L. J.; Eickhoff, J.; Crecelius, E. A.; Cragin, D. W.; Meacher, D. M.; Menzel, D. B. A market basket survey of inorganic arsenic in food. Food Chem. Toxicol. 1999, 37, 839846.

(28) Meharg, A. A.; Williams, P. N.; Adomako, E.; Lawgali, Y. Y.; Deacon, C.; Villada, A.; Cambell, R. C. J.; Sun, G. X.; Zhu, Y. G.; Feldmann, J.; Raab, A.; Zhao, F. J.; Islam, R.; Hossain, S.; Yanai, J. Geographical variation in total and inorganic arsenic content of polished (white) rice. Environ. Sci. Technol. 2009, 43, 16121617.

(29) National Research Council. Arsenic in drinking water-2001 Update; National Academy Press: Washington, DC, 2001. 218218.

(30) Williams, P. N.; Villada, A.; Raab, A.; Figuerola, J.; Green, A. J.; Feldmann, J.; Meharg, A. A. Greatly enhanced arsenic shoot assimilation in rice leads to elevated grain levels compared to wheat and barley. Environ. Sci. Technol. 2007, 41, 6854-6859.

(31) Sun, G.-X.; Williams, P. N.; Carey, A.-M.; Zhu, Y.-G.; Deacon, C.; Raab, A.; Feldmann, J.; Islam, R.; Meharg, A. A. Inorganic arsenic in rice bran and its products are an order of magnitude higher than in bulk grain. Environ. Sci. Technol. 2008, 42, 7542-7546. 
(32) Heald, S. M.; Cross, J. O.; Brewe, D. L.; Gordon, R. A. The PNC/ XOR X-ray microprobe station at APS sector 20. Nucl. Instrum. Methods Phys. Res. A 2007, 258, 215-217.

(33) Ravel, B.; Newville, M. ATHENA, ARTEMIS, HEPHAESTUS: Data analysis for X-ray absorption spectroscopy using IFEFFIT. J. Synchrotron Radiat. 2005, 12, 537-541.

(34) Lombi, E.; Susini, J. Synchrotron-based techniques for plant and soil science: opportunities, challenges and future perspectives. Plant Soil [Online early access]. DOI: 10.1007/s11104008-9876-x. Published Online: Jan 17, 2009.

(35) Lombi, E.; Scheckel, K. G.; Pallon, J.; Carey, A.-M.; Zhu, Y. G.; Meharg, A. A. Speciation and distribution of arsenic and localization of nutrients in rice grains. New Phytol., 2009, in press.

(36) Hussein, L.; Bruggeman, J. Selenium analysis of selected Egyptian foods and estimated daily intakes among a population group. Food Chem. 1999, 65, 527-532.

(37) Fordyce, F. M.; Johnson, C. C.; Navaratna, U. R. B.; Appleton, J. D.; Dissanayake, C. B. Selenium and iodine in soil, rice and drinking water in relation to endemic goitre in Sri Lanka. Sci. Total Environ. 2000, 263, 127-141.
(38) Kelly, S.; Baxter, M.; Chapman, S.; Rhodes, C.; Dennis, J.; Brereton, P. The application of isotopic and elemental analysis to determine the geographical origin of premium long grain rice. Eur. Food Res. Technol. 2002, 214, 72-78.

(39) Yadav, S. K.; Singh, I.; Sharma, A.; Singh, D. Selenium status in food grains of northern districts of India. J. Environ. Manage. 2008, 88, 770-774.

(40) Krishnan, S.; Dayanandan, P. Structural and histochemical studies on grain-fillings in the caryopsis of rice (Oryza sativa L.). J. Biosci. 2003, 28, 455-469.

(41) Cao, Z. H.; Wang, X. C.; Yao, D. H.; Zhang, X. L.; Wong, M. H. Selenium geochemistry of paddy soils in the Yangtze River Delta. Environ. Int. 2001, 26, 335-339.

(42) Meharg, A. A.; Lombi, E.; Williams, P. N.; Scheckel, K. G.; Feldmann, J.; Raab, A.; Zhu, Y. G.; Islam, R. Speciation and localization of arsenic in white and brown rice grains. Environ. Sci. Technol. 2008, 42, 1051-1057.

ES900671M 